\title{
Optical properties of colloidal gold nanoparticles implemented into a subsurface layer of fused silica
}

\author{
${ }^{1,2}$ Zheng Yu, ${ }^{2}$ Beloshenko K.S., ${ }^{2}$ Shulga S., ${ }^{3}$ Wojnarowska R., \\ ${ }^{3}$ Sheregii E.M. and ${ }^{3}$ Prokhorenko S. \\ ${ }^{1}$ Qingdao University, 308 Ningxia Road, Qingdao, Shangdong, P. R. C, 266071, \\ China \\ ${ }^{2}$ School of Radio Physics, V. N. Karazin Kharkiv National University, Kharkiv, \\ Ukraine \\ ${ }^{3}$ Center for Microelectronics and Nanotechnology, University of Rzeszow, Poland
}

Received: 27.02 .2017

\begin{abstract}
We suggest a procedure for alloying a subsurface layer of optical fused silica with nanometre-sized $\mathrm{Au}$ granules. The alloying process involves two-stage heating of both a specimen base, using a gas burner, and a gold island film, using a $\mathrm{CO}_{2}$-laser beam with the parameters $\lambda=10.6 \mu \mathrm{m}$ and $P \sim 20 \mathrm{~W}$. We study the structural characteristics of the resulting alloy layer depending on the exposure time and identify the optical absorption bands at different stages of the implanting procedure. The plasma frequency of the gold nanoparticle matrix is determined, using the experimental optical spectra of our specimen.
\end{abstract}

Keywords: gold nanoparticles, quartz, nanostructures, thermostimulated implantation, interband transitions in metals

PACS: 42.25.Fx, 42.70.Ce, 61.46.-w, 71.55.Ak

UDC: 535.421

\section{Introduction}

Physical properties of quartz have attracted much attention of researchers because both fused and crystalline quartz modifications are widely used in various fields of science and technology. In particular, a favourable combination of mechanical, thermal and optical properties of fused silica has stipulated its wide applications in spectroscopy, fibre optics and, recently, in fabrication of composites.

Unique optical properties of noble-metal nanoparticles, e.g. a possibility for exciting plasmons (or a so-called surface plasmon resonance), are useful for implementing a number of modern analytical methods [1-3]. Simultaneously, new composite materials such as granular films placed in the layer of bulk substance have also conditioned a surge of interest [4]. The island films inside the matrices of solid materials have been obtained, e.g., through ion implantation [5], sol-gel technology [6], and a combined evaporation of base and metal [3]. Nevertheless, these methods reveal some drawbacks, including technological difficulties that arise while obtaining colloids with preset optical properties.

In addition to implanting, modification of metal nanoparticles implanted in dielectrics by means of laser beams is also of great interest [7]. For example, the influence of Ar+ laser beam on a silicate glass doped with $\mathrm{Ag}+$ ions has been analyzed in Ref. [8]. It has been shown that the 
exposure to optical radiation results in forming of Ag-particle chains that give rise to optical dichroism of the glass surface.

In the present study we consider a method for thermostimulated implantation of gold island films into near-surface layers of melted quartz. This technology has already been tested for the case of $\mathrm{Ag}-\mathrm{SiO}_{2}$ system [9]. There are several particulars which should be taken into account when performing thermostimulated implantation of gold into a near-surface layer of melted quartz: (i) the fusion temperature of gold is equal to $1064.18^{\circ} \mathrm{C}$, whereas for silver it is somewhat lower, $961.78^{\circ} \mathrm{C}$ [10], (ii) the radius of the gold atoms is equal to $0.134 \mathrm{~nm}[10]$, and (iii) the emissivities in the optical region 8-14 $\mu \mathrm{m}$ amount to 0.01 and 0.05 respectively for gold and silver [10].

Below we will show that the surface layer of fused silica can be doped via irradiating, with a $\mathrm{CO}_{2}$-laser beam, a thin Au film vacuum-deposited on silica, whenever a specimen has been heated preliminarily using a gas burner.

\section{Preparation and characterization of specimen}

In order to perform a thermostimulated gold implantation, polished plane-parallel silica plates had to be thoroughly selected. The plates were chosen to have the square of $10 \mathrm{~cm}^{2}$ and the thickness of $2 \mathrm{~mm}$. At the first stage, a thin $(\sim 10 \mathrm{~nm})$ Au film was deposited onto one side of the plate in the $5 \times 10^{-5}$ Torr vacuum chamber at the room temperature. Then, at the second stage, the opposite side of the plate, which is free of Au film, was subjected to preliminary heating in the air, using a gas burner. The temperature inside the heating spot was controlled to be in the interval $980-1000^{\circ} \mathrm{C}$. The duration of this preliminary heating was $3 \mathrm{~min}$. At the third stage, the plates in the air were irradiated from the film side by a continuous-wave $\mathrm{CO}_{2}$ laser. Namely, we employed a laser ILGN-704 with the Gaussian beam shape, the wavelength $\lambda=10.6 \mu \mathrm{m}$, the power $P \sim 20 \mathrm{~W}$, and the effective diameter $D_{\text {eff }} \approx 3-4 \mathrm{~mm}$ of the laser spot. The duration of the irradiation procedure was $15 \mathrm{~min}$. The surface-heating temperature at this stage was controlled with an infrared camera Optris PI 160.

To understand qualitatively the process of gold implantation under the action of laser beam, visual observations of colour changes occurring for the $\mathrm{Au}$ film were carried out. Initially the $\mathrm{Au}$ film is green. Then its colour changes to crimson when the irradiation begins and, finally, the film becomes yellow at the end of the implantation procedure. It is evident that these colour changes are caused by some transformations in the inner film structure caused by thermodiffusion processes. In the course of these processes, the Au film on the surface of the silica plate transforms into a two-dimensional colloid. As a consequence, the film acquires different absorption characteristics that correspond to different plasma resonant conditions which, in their turn, manifest themselves in different colours.

After 3 min long heating of the Au film with the laser beam, the film starts to shine intensively and the process reaches quickly a stage of a pure white glow. Our measurements with an infrared camera have testified that the surface temperature is about $1100^{\circ} \mathrm{C}$ at this stage. It is well known from the previous experiments for the visible spectral range that the Au films with the thicknesses of about $10 \mathrm{~nm}$ reveal a large absorbance. The latter is the reason for a bright thermal glow of the films heated up to high temperatures, owing to the Kirchhoff's law of thermal radiation. Therefore, it is important to maintain this temperature and the other implantation conditions for preventing evaporation of gold from the surface of the silica plate. Then the changes in the film colour to yellow or orange tints would indicate beginning of the evaporation process. In this case the laser power should be reduced to lower vales. Finally, disappearance of the white-

Ukr. J. Phys. Opt. 2017, Volume 18, Issue 2 
colour glow implies that the implantation process is successfully completed. In other words, there is no metal nanoparticle on the surface of silica, which reflects the $\mathrm{CO}_{2}$ laser radiation.

The quality of the two-dimensional gold colloid which is implanted at the subsurface of the fused-silica substrate was further controlled by means of the measurements of mechanical hardness of the specimen and its resistance to nitric acid. These tests had demonstrated high stability of the plasma layer, since the gold penetrated into silica was protected from the action of the acid and, under normal conditions, its state remained invariable for arbitrarily long times.

We studied the surface topography with an atomic force microscope Innova ${ }^{\circledR}$, which enabled us to obtain detailed images of the specimen surface. In particular, Fig. 1a presents a specimen image observed in the constant-height mode, while the image displayed in Fig. 1b is obtained in the implantation mode. One can conclude that the resulting surface has the shape of array, with circular hills having some craters inside. The protruding parts of the surface have numerous lightcoloured elements. Obviously, the exact origins of these craters require further studies. One of the possible reasons for their appearance can be the fact that gold reacts with oxygen at high enough temperatures $\left(\sim 1000^{\circ} \mathrm{C}\right)$ and, as the temperature decreases down to $20^{\circ} \mathrm{C}$, the reverse reaction can occur, resulting in oxygen outburst.

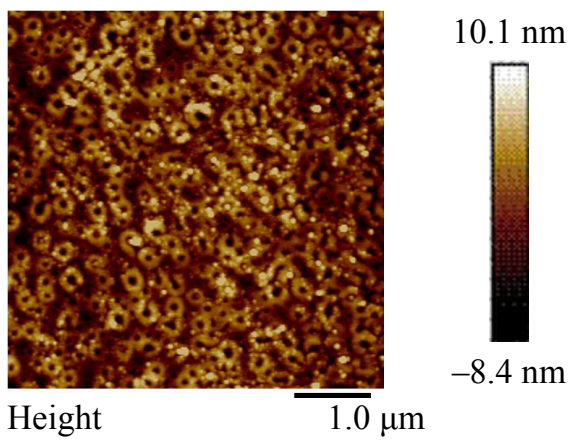

(a)

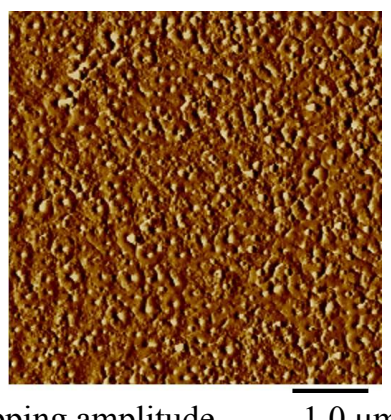

(b)

Fig. 1. Atomic force microscopy images of our specimen obtained after implanting $A u$ granules into the subsurface layer of silica plate, as observed in constant-height (a) and implantation modes

The shape of the surface is believed to be formed through some deformations of the silicaplate surface by the Au granules in the places where the granules are mostly located under the quartz surface. Unfortunately, the images of the surface obtained by us do not reflect clearly the sizes of the Au granules and their spreading into the depth of the silica layer. They only show the surface geometry of the layer after the Au granules have penetrated into quartz. Nevertheless, issuing from the average diameter of the craters, it is possible to estimate the sizes of the gold granules as being about $1-3 \mathrm{~nm}$.

Although the doping mechanism needs a more detailed elaboration, here we not go beyond considering it as a process of emission of electrons into silica and their trapping inside it (see Ref. [1]). Apparently, the expected doping process occurs at the initial stage, when the temperature in the central zone reaches the melting point of gold. The molten particles are positively charged, and an electrostatic field is induced between them and the traps, thus providing detachment of $\mathrm{Au}^{+}$ ions and their transport to that traps. This process is repeated many times and, as a result, it leads to precipitation of the Au granules in the surface layer of silica. Note that the granule precipitation is facilitated by a remarkable porosity of fused silica: the ratio of its density to the density of crystalline $\mathrm{SiO}_{2}$ is known to be equal to 0.83 . 
We suggest that the transformations occurring in silica are split into several phases, among which transition from $\beta_{2}$-tridymite phase to $\alpha$-cristobalite phase prevails [2]. A hexagonal grid in the latter phase has some defects in the form of structural distortions of the bonds among the neighbouring tetrahedra and the positions of oxygen atoms. Due to the bonds among the adjacent tetrahedra provided by the oxygen atoms, the structure of the quartz glass involves some cavities, which are bounded in space by bridging oxygen atoms [9]. These defects can fuse into micropores, and their concentration is expected to reach its maximum just in the silica subsurface layer. The first reason for that is a thermal gradient that causes preferential occurrence of defects within the low-temperature areas [3]. The second reason is that the thermal minimum at the stage of laser irradiation appears to be directly under the gold granules, since gold reflects almost completely the irradiating $\mathrm{CO}_{2}$-laser beam. Still another mechanism can be associated with some structural transformations occurring directly in the gold film.

\section{Optical properties}

An important additional information about the structure of fused silica doped by the Au granules can be derived from the optical properties of our specimen. These properties are to be compared with the optical transmission spectrum $T(\lambda)$ of the corresponding plates made of pure quartz. The optical spectra have been measured using a standard SF-26 spectrophotometer. The diameter of the probe beam has been chosen to be slightly smaller than the area of the coloured sectors. All the measurements have been performed within the wavelength band $\lambda=270-620 \mathrm{~nm}$ that covers both the edge of the interband absorption and the absorption band of colloidal Au related to the surface plasmons. Our main results are presented in Fig. 2 as a dependence of the optical density $D=\ln T$ upon the light frequency $\omega=2 \pi c / \lambda$, as measured at different stages of the process (see also Refs. $[2,11])$. The data reported in Fig. 2 demonstrates that the optical density spectra undergo some changes during the process of thermal exposure.

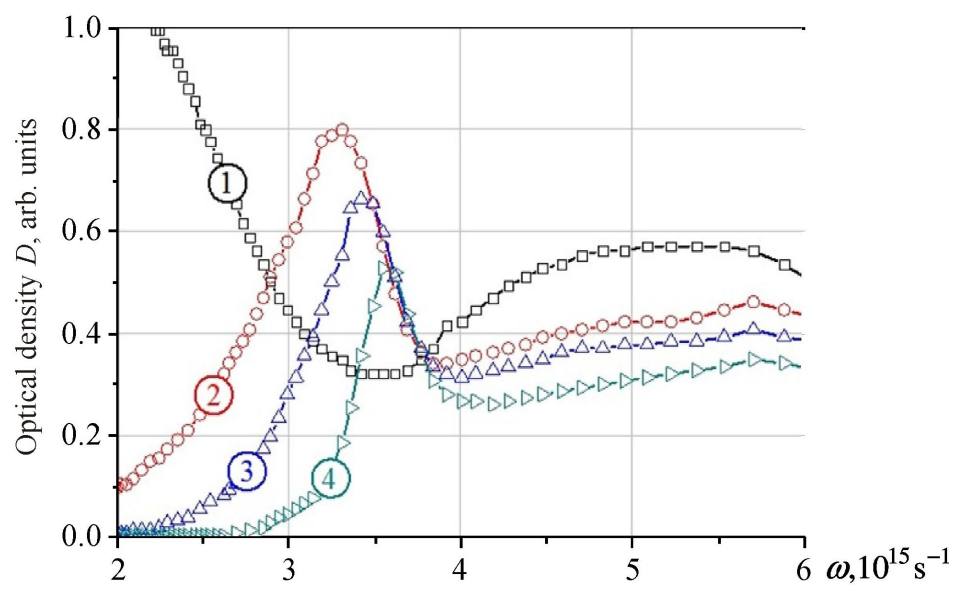

Fig. 2. Frequency dependences of the optical density for (1) island film, (2) granulated film after heating the opposite side of the plate with a gas burner, (3) granulated film after 7 min long irradiation of the film with $\mathrm{CO}_{2}$ laser and (4) gold film implanted into the fused-silica matrix.

As already mentioned, the Au film is initially green, which corresponds to curve 1 in Fig. 2 related to the film with irregular boundaries of islands. After beginning of the heating procedure, the film becomes crimson. The process corresponds to curve 2 in Fig. 2, with the maximal absorption being achieved at the frequency $3.3 \times 10^{-15} \mathrm{~s}^{-1}$. This can be considered as an evidence of 
the fact that some 'hills' appear in the islands because of a 'grumous' decay of the film. In its turn, this can be explained by different rates of the volume and surface diffusions [2]. The film structure at this stage becomes granulated, while the islands acquire spherical shapes and the bridges between the islands at the film disappear altogether.

Afterwards, the $\mathrm{CO}_{2}$-laser irradiation generates further structural changes. After $7 \mathrm{~min}$ long irradiation, the film changes its colour to 'onion-skin'. As seen from Fig. 2 (curve 3), the absorption band at this stage is located inside the high-frequency region. The maximum is shifted towards higher frequencies $\left(3.4 \times 10^{-15} \mathrm{~s}^{-1}\right)$ and remains less than the maximum typical for the curve 2. Simultaneously, the half-width $\gamma=0.4 \times 10^{-15} \mathrm{~s}^{-1}$ of the band is less than that of the absorption band corresponding to the curve $2\left(\gamma=0.8 \times 10^{-15} \mathrm{~s}^{-1}\right)$. These two factors demonstrate the following facts: (i) both the dielectric factor of the granule environment and the colloid filling factor $q$ are changed, and (ii) the sizes of the granules decrease. This, in turn, results in narrowing of the absorption band. Finally, the film becomes orange at the end of the implantation procedure and the absorption maximum is located at $3.6 \times 10^{-15} \mathrm{~s}^{-1}$ (see curve 4 in Fig. 2). Hence, the data obtained from both the spectrophotometic and the atomic-force microscopic measurements show that the granules differ slightly in their diameter and, therefore, the classical model developed in Refs. [3-5] can be readily applied for their description.

According to this model, the self-resonant electron frequency in a granule can be written as

$$
\omega_{0}=\frac{\omega_{p}}{\sqrt{\varepsilon_{M}+2 \varepsilon_{0}}},
$$

where $\omega_{p}$ is the plasma frequency of gold, of which exact value is insufficiently known so far, $\varepsilon_{M}$ denotes the dielectric constant determined by the interband transition in metals, and $\varepsilon_{0}$ is the dielectric constant of granule environment. A unique feature of the experiments implemented by us is that we have obtained the spectral data corresponding to the implantation dynamics. Then we can determine $\varepsilon_{M}$ with our results and calculate $\omega_{0}$. Basing on the latter value, we are in a position to estimate the parameter $\omega_{p}$. In our calculations we imply the following proportion:

$$
\frac{\omega_{0 \text { im }}^{2}}{\omega_{0 \text { air }}^{2}}=\frac{\left(\omega_{M}+2 \varepsilon_{\text {quar }}\right)}{\left(\varepsilon_{M}+2 \varepsilon_{\text {air }}\right)},
$$

where $\omega_{0 i m}$ is the cyclic frequency related to the absorption band maximum of the implanted colloid (see curve 4 in Fig. 2), $\omega_{\text {0air }}$ the cyclic frequency related to the absorption band maximum of the colloid surrounded by air (see curve 2), while $\varepsilon_{\text {air }}$ and $\varepsilon_{\text {quar }}$ are the dielectric constants of respectively air and quartz. If we take $\varepsilon_{\text {air }}=1$ and $\varepsilon_{\text {quar }}=2.13$ (see Ref. [2]), the result $\varepsilon_{M}=9.3$ follows immediately, which agrees completely with the data obtained earlier $[4,5]$. Although the detailed mathematical analysis of the colloidal absorption band has been performed for silver only [12], the current computation can easily be applied to our experiments, using the optical constants of gold.

\section{Conclusions}

In the present work we have reported on a successful attempt to produce the alloy of the optical quartz glass and the colloidal $\mathrm{Au}$ (with the granule sizes equal to $1-3 \mathrm{~nm}$ ) by means of thermostimulated implantation into a thin $(\sim 50-100 \mathrm{~nm})$ near-surface layer of $\mathrm{SiO}_{2}$. This colloid has the distinct absorption band centred at the frequency $3.6 \times 10^{-15} \mathrm{~s}^{-1}$, which corresponds to the 
effective size of the gold granule.

The technique described above can be applied only to fused quartz because this material has a high enough melting temperature $\left(1773^{\circ} \mathrm{C}\right)$ combined with a sufficiently high absorption factor at the optical wavelength $\lambda=10.6 \mu \mathrm{m}$. Moreover, the material under study is sufficiently resistant to heating with a laser beam and has a porous structure, thus allowing for the appearance of granules in the near-surface region of this matrix. It also important that the island film has a discrete structure and it can be heated with a laser beam to the temperatures corresponding to those of metal melting. Furthermore, we must emphasize the fact that it would have been difficult to obtain so high standards with the similar self-resonant frequency in the granule. The current method allows obtaining the colloids having the absorption maximum located at $(3.6 \pm 0.1) \times 10^{-15} \mathrm{~s}^{-1}$, with a high degree of reproducibility. The latter fact is very important for many applications in nanobiosystems that make use of the plasmon resonance. In other words, the $\mathrm{Au}-\mathrm{SiO}_{2}$ system manifests strong adhesive properties [13], an enhanced Raman scattering of molecules which are adhesive on the surface of $\mathrm{Au}-\mathrm{SiO}_{2}$ [14], and a sufficient chemical stability for wide-range chemical compounding. It is also worthwhile that our alloyed layers can be used in many other optoelectronic applications, e.g. for durable labelling and colouring items of melted quartz that go into production of waveguide trails and filters, and for some other purposes.

\section{References}

1. Ageev L, Miloslavskii V and Makovetskii E, 2007. Coloring of silica glass with silver nanoparticles. Opt. Spectrosc. 102: 442-448.

2. Miloslavsky V, Makovetsky E, Ageev L and Beloshenko K, 2009. Fused silica as a composite nanostructured material. Opt. Spectrosc. 107: 811-815.

3. Hampe W, 1958. Beitrag zur deutung der anomalen optischen eigenschaften feinstteiliger metallkolloide in großer konzentration, Zeit. Phys. 152: 476-494.

4. Shklyarevskii I and Pakhmov P, 1973. Separation of the contribution of free and bound electrons into real and imaginary parts of the dielectric constant of gold. Opt. Spectrosc. 34: 163-166.

5. Shklyarevskii I, Pakhmov P and Korneeva T, 1973. Plasma resonance in granular silver and gold films. Opt. Spectrosc. 34: 729-736.

6. Nahal A, Khalesifard H R M and Mostafavi-Amjad J, 2004. Photothermal-induced dichroism and micro-cluster formation in $\mathrm{Ag}^{+}$-doped glasses. Appl. Phys. B. 79: 513-518.

7. Ageev L A, Miloslavsky V K, Makovetsky E D, Beloshenko K S and Stronsky A V, 2007. Thermostimulated implantation of nanoscaled Ag particles into a quartz glass using a $\mathrm{CO}_{2}$ laser beam. Functional Mater. 14: 24-31.

8. Mostafavi A J and Khalesifard H R M, 2008. Micro-channels over the glass surface made by interaction of $\mathrm{Ar}+$ laser beam and $\mathrm{Ag}+/ \mathrm{Na}+$ ion-exchanged glasses. Int. J. Opt. Photon. 2: 3942.

9. Leco V and Mazurin O. Quartz glass properties. Leningrad: Nauka (1985).

10. Gaussorgues G and Chomet S. Infrared thermography, Vol. 5. Springer Science \& Business Media (2012).

11. Hass G, Francombe M H and Hoffman R W. Physics of thin films: Advances in research and development. Elsevier (2013).

12. Ageev L A, Beloshenko K S, Makovetsky E D and Miloslavsky V K, 2009. Implantation of periodic structures formed by silver particles into quartz glass. Opt. Spectrosc. 107: 796-802.

Ukr. J. Phys. Opt. 2017, Volume 18, Issue 2 
13. Li B and Logan B E, 2004. Bacterial adhesion to glass and metal-oxide surfaces. Colloids and Surf. B: Biointerfaces. 36: 81-90.

14. Chang R, Surface enhanced Raman scattering. Berlin: Springer Science \& Business Media (2013).

Zheng Yu, Beloshenko K.S., Shulga S., Wojnarowska R., Sheregii E.M. and Prokhorenko S. 2017. Optical properties of colloidal gold nanoparticles implemented into a subsurface layer of fused silica. Ukr.J.Phys.Opt. 18: $102-108$

Анотація. Запропоновано процедуру легування підповерхневого шару оптичного плавленого квариу гранулами золота нанометрових розмірів. Процес легування включає двоступеневе нагрівання бази зразка за допомогою газового пальника і плівки з острівиями золота із використанням променя $\mathrm{CO}_{2}$ лазера з параметрами $\lambda=10,6$ мкм $i \mathrm{P} \sim 20 \mathrm{Bm}$. Досліджено структурні характеристики одержаного шару сплаву залежно від часу експозиції, $a$ також ідентифіковано оптичні смуги поглинання на різних стадіях процедури імплантації. 3 використанням експериментальних оптичних спектрів нашого зразка визначено плазмову частоту матриці наночастинок золота. 